\title{
Aminoglutethimide: a 'side-effect' turned to therapeutic advantage
}

\author{
S. W. M. Hughes \\ B.Pharm., D.C.C., M.P.S., M.I.Biol. \\ D. M. BURLEY \\ M.B., B.S., M.R.C.S., L.R.C.P. \\ Medical Division, CIBA Laboratories, Horsham, Sussex
}

\begin{abstract}
Summary
Aminoglutethimide was introduced as an anticonvulsant drug in the U.S.A. in 1960.

The occurrence of a number of side-effects, including several endocrine effects such as goitrogenesis, sexual precocity and virilization, led to its withdrawal.

Further investigation indicated that the drug inhibited adrenal biosynthesis, particularly of aldosterone, cortisol and androgens, probably by interfering with the conversion of cholesterol to delta-5pregnenolone.

Aminoglutethimide has also been shown to modify the extra-adrenal metabolism of cortisol.

The possible clinical applications of these 'sideeffects' are discussed.

Aminoglutethimide was first described in the pharmacological literature in 1956 . It was clinically evaluated as an anti-convulsant and became commercially available in the United States in $\mathbf{1 9 6 0 .}$ Six years later it was withdrawn from the market at the request of the United States Food and Drugs Administration on account of side-effects. It is the purpose of this paper to describe the events leading to the withdrawal of aminoglutethimide and also to review the subsequent biochemical and clinical investigations which have resulted in the previously unwanted side-effects of this drug being utilized to clinical advantage.
\end{abstract}

\section{Anticonvulsant activity}

In 1956 Gross et al. reported the structure, activity and metabolism of a series of $\alpha, \alpha$ disubstituted glutaric acid imides. A series of compounds based on $\alpha$-phenyl- $\alpha$-ethyl glutarimide (glutethimide) which had known sedative-hypnotic and anticonvulsant activity, was examined in mice and $p$ - $(\alpha$-aminophenyl)- $\alpha$-ethyl glutarimide (aminoglutethimide) was shown to have markedly greater anticonvulsant activity, but considerably less sedative-hypnotic effect, than the parent compound. Clinical evaluation proceeded in Europe and North America and amino- glutethimide was marketed as an anticonvulsant in the United States in May 1960.

Reports on the therapeutic use of aminoglutethimide appeared in both the North American medical literature (Lambros, 1958; LaVeck, 1960; Pearce, 1960; Aguilar, Martin \& McNaughton, 1961) and the European medical literature (Guareschi, Giannelli \& Marinato, 1956; Sheehan, 1958; Fabisch, 1959; Defer, 1960; Verdeau-Pailles, 1961). All these papers reported varying degrees of efficacy in either grand mal, petit mal or psychomotor epilepsy. Nevertheless, in one study, of 2 years' duration, using aminoglutethimide with other anticonvulsants, it was found to be impossible to discontinue any of the companion drugs (Aguilar et al., 1961) and in 1962 the American Medical Association's Council on Drugs (Journal of the American Medical Association, 1962), reviewing new drugs and developments in therapeutics, described aminoglutethimide as a 'moderately effective' anticonvulsant for oral treatment of various types of convulsive seizure. The Council concluded that in view of its limited efficacy and high frequency of untoward reactions, aminoglutethimide was only indicated as a supplement to other anticonvulsants in those patients not responding to conventional therapeutic regimes. At that time side-effects were reported to occur in almost half of the patients treated. These commonly included morbilliform rashes, dizziness, drowsiness, behavioural changes, ataxia, headache, leukopenia, respiratory depression and, more rarely, exfoliative dermatitis and one case of agranulocytosis with ulcerative stomatitis.

Thus, although not highly regarded as an anticonvulsant aminoglutethimide found a place as a second-line drug, and in 1966 it was estimated that it was being used by approximately 5000 patients annually.

\section{F.D.A. withdrawal}

In 1963 Cash, a Detroit paediatrician, noted the occurrence of goitrous hypothyroidism and adrenal insufficiency in an $\mathbf{8}$ year-old female patient who had 
been admitted to the Sinai Hospital. The patient exhibited a bronze skin typical of Addison's disease but had no history of adrenal disorder. It was, however, noted that she was an epileptic and had received aminoglutethimide for the previous 5 months. Studies in this patient, and others receiving aminoglutethimide, and experimental work in rats and dogs demonstrated that the drug could produce histological changes in the adrenals suggesting a block of steroid biosynthesis (Camacho et al., 1966). In 1964 Rallison, Tyler \& Kumagi described thyroid enlargement and hypothyroidism in three epileptic children receiving the drug. Withdrawal of the aminoglutethimide in these children resulted in the disappearance of the goitre and restoration of normal thyroid function, thus confirming that the goitres were drug-induced. These setbacks for aminoglutethimide were followed in 1965 by the publication of a case of congenital female pseudohermaphroditism which was considered to be due to anticonvulsant drugs, which included aminoglutethimide, taken by the mother (Iffy et al., 1965). Finally during this same period the manufacturers informed the Food and Drugs Administration (FDA) that they had received reports of sexual precocity in children receiving the drug.

Thus in February 1966 aminoglutethimide was recalled from the market (F.D.A. press release 16 February 1966). The F.D.A. stated that it had requested this action since the effectiveness of the drug in the treatment of convulsions was in doubt and that clinical experience had shown that it may cause sexual precocity in some children, masculinization of young females and other untoward effects.

Following the commercial withdrawal, aminoglutethimide was immediately reinstated as an Investigational New Drug. It was, therefore, possible to continue to supply epileptic patients still requiring the drug and also to make it available to research workers wishing to investigate its activities as a metabolic inhibitor. To date, research has centred around the effects of the drug on thyroid metabolism and adrenal and gonadal steroid biosynthesis.

\section{Anti-thyroid effect}

Following the initial report of goitres and hypothyroidism in children treated with aminoglutethimide, further animal studies were initiated to investigate the problem. Pittman \& Brown (1966) administered the drug for 8 days to intact and hypophysectomized rats on a low iodine diet. The intact animals showed a marked increase in thyroid weight and depression of radio-iodine uptake. Similar results were also obtained with another group of rats given amphenone B which is known to have a goitrogenic action. The hypophysectomized animals showed none of these findings with the exception of a slight reduction in radio-iodine uptake. These studies, therefore, confirmed that aminoglutethimide interferes with thyroid metabolism and that it has a goitrogenic action.

When Rallison et al. (1964) first reported the effects of aminoglutethimide on thyroid metabolism, they based their original suggestion of a block in the organification of iodine on the evidence obtained from three children who showed low protein-bound iodine, and low butyl extractable iodine values, a high thyroidal uptake of radio-iodine and a discharge of more than $50 \%$ of thyroidal radioactivity following the administration of thiocyanate. Extraction and chromatography of plasma and urine failed to reveal any abnormal iodinated compounds. Four additional children, also receiving the drug, were found to be clinically euthyroid and exhibited no abnormalities of protein-bound iodine or radioiodine uptake. These workers have since investigated the nature of the antithyroidal effects of aminoglutethimide in rats and have consistently demonstrated thyromegaly, diminished production of thyroxine and di-iodotyrosine and an accumulation of thyroidal inorganic iodide (Rallison, Kumagi \& Tyler, 1967). The block in the organificiation of iodine was found to be similar to the action of propylthiouracil and aminobenzene derivatives to which aminoglutethimide bears a structural resemblance. They concluded that the unpredictability of antithyroidal activity among their seven patients receiving aminoglutethimide still required explanation and the experimental evidence accumulated to date suggests that dosage, or duration of treatment, are unlikely to be responsible; individual hypersensitivity and genetic factors are possibly involved.

\section{Inhibition of steroid biosynthesis}

The early reports suggesting inhibition of adrenal steroid biosynthesis by aminoglutethimide were based on the findings in two children who had exhibited clinical manifestations and serum electrolyte changes typical of adrenal insufficiency. In both of these patients the administration of ACTH failed to produce any increase in plasma or urinary 17 hydroxycorticoids (17OHCS) and these patients still remained unresponsive to ACTH 6 and 10 months respectively after withdrawal of the drug. That aminoglutethimide was responsible for the adrenal insufficiency, and not other anticonvulsants being taken concomitantly, was demonstrated in one patient whose condition improved after withdrawal of the aminoglutethimide but deteriorated quickly when the drug was re-administered (Camacho et al., 1966 and 1967). Furthermore aminoglutethimide had been fed to puppies and these animals had subsequently been shown to be unresponsive to ACTH (Camacho et al., 1966) and studies in rats showed 
that the drug induced adrenal hypertrophy (Pittman \& Brown, 1966). The systematic biochemical and clinical investigation of the effects of aminoglutethimide on the adrenal glands which followed is reviewed below.

\section{Histological evidence of adrenocortical inhibition}

Post-mortem adrenal gland specimens from fourteen patients who had received aminoglutethimide (in addition to one or more other anti-convulsants) were examined. Striking histological changes were seen in ten patients. These included cellular hypertrophy, cytoplasmic vacuolation and excessive accumulation of lipid in the cortex of the glands (Camacho et al., 1966).

Similar findings have been described more recently by Givens, Coleman \& Britt (1968) who administered aminoglutethimide (750-1000 mg/day) to four adults awaiting adrenalectomy. Three patients had metastatic carcinoma of the breast, two were euadrenal and one was receiving a suppressive dose of prednisolone. The fourth patient had metastatic non-functioning adrenocortical carcinoma. The anatomical changes found in the euadrenal subjects were: an increase in size and weight of the adrenal glands, a marked golden-yellow colour, an increased size of the zona fasciculata, marked diminution in the size of the zona glomerulosa and an increase in the lipid-positive staining deposits in the cells of the zona fasiculata. The latter observation was also present in the patient receiving prednisolone. Similar changes have also been demonstrated in rats and puppies receiving aminoglutethimide (Camacho et al., 1966).

\section{Mechanism of adrenocortical inhibition}

Experimental studies undertaken by Wilroy, Camacho \& Trouy (1966) in rats and dogs, the additional work in rats and the in vitro studies of Dexter et al. (1966 and 1967), have shown that aminoglutethimide produces a decrease in corticosterone production which is accompanied by an increase in plasma ACTH. Marked hypertrophy of the adrenals occurs, this being due to both the adrenal growth-promoting effect of the increased endogenous ACTH and also to the increased water, cholesterol and cholesterol esters found in the glands. There was no evidence to suggest that the conversion of pregnenolone to corticosterone was impaired and it was, therefore, concluded from these studies that the drug inhibits conversion of cholesterol to pregnenolone and that the accumulation of cholesterol in the adrenal glands can be attributed to the combined effects of the increased endogenous ACTH and a direct action of the drug.

Cash et al. (1967) have demonstrated that aminoglutethimide interferes with the enzymic conversion of cholesterol to delta 5-pregnenolone by inhibiting the adrenal mitochondrial cholesterol side-chain cleaving enzyme system known as the 'desmolase complex'. The exact point at which inhibition takes place remains uncertain but the studies of Kahnt \& Neher (1966) utilizing beef adrenal slices, in vitro, suggest that the drug inhibits $20 \alpha$-hydroxylation of cholesterol. Kowal (1967) has confirmed these findings and produced complete inhibition of steroidogenesis with aminoglutethimide $(0.05 \mathrm{~m}$-mole) in monolayer cultures of functional adrenal tumour cells. The effects of ACTH on cell morphology and glucose consumption were not inhibited and thus the drug appeared to inhibit the steroidogenic enzymes directly at levels producing no toxic effects on the living cell. This investigator has also shown competitive inhibition of $11 \beta$-hydroxylation by high concentrations of aminoglutethimide. It should also be noted that like metyrapone, aminoglutethimide has been shown to decrease 11- $\alpha$-hydroxylation and increase $21 \alpha$-hydroxylation of progesterone in vitro (Sheppard, Beasley \& Wacker, 1966).

Experimental studies in humans followed as a logical extension of the in vitro studies and work in animals. Camacho et al. (1967) and Cash et al. (1967) showed that the inhibitory effect of aminoglutethimide on steroidogenesis blocks the production of adrenal cortisol, aldosterone and androgens and also their hormonally active precursors. These findings were confirmed by Fishman et al. (1967) in both normal healthy volunteers and patients. In addition both investigators showed that the administration of the drug decreases the cortisol secretion rate and lowers the level of plasma and urinary 17-OHCS. In general, inhibition of cortisol secretion was most obvious in patients with Cushing's syndrome due to autonomous steroid secretion by adrenal tumours. In normal subjects, large doses of aminoglutethimide were accompanied by increases in plasma ACTH and it is likely that these compensatory increases were responsible for the maintenance of near-normal cortisol secretion rates and plasma 17OHCS levels in these subjects. The most consistent effect of the drug was on aldosterone secretion rates which were lowered in patients with primary aldosteronism as well as in patients with Cushing's syndrome and normal healthy subjects. The fall in aldosterone secretion was accompanied by an increase in urinary sodium, a decrease in urinary potassium, a rise in plasma renin activity and some lowering of blood pressure in hypertensive patients. Schteingart \& Conn (1967) have reported that the excretion of 17-ketosteroids (17KS) in the urine falls just after commencement of therapy with aminoglutethimide but later returns to initial values. Investigation of the separate $17 \mathrm{KS}$ fractions has shown that the fall primarily involves 11-oxy-17-ketosteroids, whereas 
11-deoxy-17-ketosteroids (etiocholanolone and androsterone) either do not alter or have a slight tendency to rise (Horky \& Küchel, 1969).

Long-term therapy with high doses of aminoglutethimide may, particularly in children, result in a decreased adrenal reserve capacity which can persist for a considerable period following withdrawal of the drug (Camacho et al. 1967). On the other hand, Fishman et al. (1967) considered that in most patients the inhibition is quickly reversible on discontinuing medication.

\section{Inhibition of gonadal steroid production}

Since pregnenolone is a major precursor of all steroid hormones aminoglutethimide would also be expected to interfere with the synthesis of gonadal androgens and oestrogens. To date comparatively little work has been published on this aspect of the action of aminoglutethimide. Pittman \& Brown (1966) described ovarian enlargement in intact rats and a suggestion of uterine enlargement in hypophysectomized rats treated with the drug. Eversole \& Thompson (1967) and Zavadil, Schreiber \& Kmentova-Zbuzkova (1968) have shown that in rats, large doses of aminoglutethimide stopped the oestrous cycle and produced sterility associated with enlarged follicular ovaries. Gaunt, Steinetz \& Chart (1968) confirmed the latter findings and concluded that the effects of long-term administration of aminoglutethimide in females were consistent with the hypothesis that it reduced oestrogen secretion, as judged by decreased uterine weight in intact but not in castrated animals. Anomalous increases in body weight were not seen in males, or in females after ovariectomy. In this context it should be noted that Philbert et al. (1966) failed to notice any changes in the menstrual cycle of six women who had received aminoglutethimide for several weeks, nor were there any significant changes in the oestrogen and pregnanediol levels in three hirsute women who were known to have normal ovarian function. Cash, Petrini \& Brough (1969) have described ovarian dysfunction and resulting virilization of a young female following aminoglutethimide (1000 mg daily), but it should be noted that treatment was of 6 years duration.

Gaunt et al. (1968) found no evidence in rats to suggest inhibition of testicular function and it appears, therefore, that, in animals, gonad steroidogenesis may be affected by aminoglutethimide in the female but that the adrenal gland is far more susceptible to the drug.

\section{Peripheral metabolism of steroids}

In addition to its effect as an inhibitor of adrenal steroid synthesis, and possibly gonadal steroid synthesis, it has been shown that aminoglutethimide also alters the extra-adrenal metabolism of cortisol, with the result that urinary $170 \mathrm{OCS}$ have been found to be disproportionately low in relation to the cortisol output and plasma 17OHCS determinations (Fishman et al. 1967; Schteingart \& Conn, 1967). Possible effects of the drug on assay procedures were discounted by Fishman et al. (1967) and recent work by Hagen \& Butler (1969) now suggests that the catabolism of cortisol is influenced either by inhibition of the $11 \beta$-dehydrogenase system or possibly in the stimulation of the delta 4-3-keto reductase system. These possiblities have emerged as a result of work on the catabolism of cortisol-4- ${ }^{14} \mathrm{C}$ before and after aminoglutethimide in a patient with Addison's disease. In this work the concentrations of several urinary metabolites were recorded: tetrahydrocortisol excretion doubled, whilst tetrahydrocortisone and cortolone decreased. There was no significant change in the $17 \mathrm{KS}$.

\section{Comparisons with chemically-related drugs}

Although the evidence now available has confirmed beyond doubt that aminoglutethimide can affect thyroid and adrenal cortical metabolism, it is nevertheless noteworthy that the original reports of endocrinological side-effects attributed to the drug were all reported in patients who were receiving additional anticonvulsants. It is, therefore, of interest to review the literature on the side-effects of the main drugs concerned-the barbiturates, phenytoin and primidone-particularly since all these drugs may be considered to be chemically related to aminoglutethimide.

Phenytoin is known to affect the catabolism of plasma cortisol by increasing 6-hydroxylation, but standard ACTH stimulation tests yield normal values for 17OHCS and plasma cortisol in patients receiving the drug (Werk, MacGee \& Sholiton, 1964). Phenytoin has, however, been reported to produce signs of virilization in young females and young males (Livingstone, 1956), hirsutism (Livingstone, Petersen \& Boks, 1955) and hypertrichosis, brown pigmentation and acne (Bray, 1959). Sparberg (1963) has reviewed the literature relating to the effect of phenytoin on the pituitary-adrenal axis and has concluded that depressed adrenal cortical function and diminished response of the pituitary hypothalamic axis can occur. This depression is not clinically significant but may lead to misdiagnoses of adrenal cortical insufficiency or panhypopituitarism. Sparberg (1963) has also reviewed the effect of phenytoin on thyroid metabolism. It appears that this drug competes for the binding sites of thyroxine-binding globulin thus producing a low serum protein-bound iodine. There is no evidence that the drug actually affects thyroid function in man and it should be noted that Rallison et al. (1967) whilst examining 
the effects of aminoglutethimide on thyroid metabolism in rats, also examined the effects of phenytoin, primidone and glutethimide under the same conditions and failed to find any significant changes in thyroid function.

The literature for the barbiturates, primidone and glutethimide contains no reference to endocrinological side-effects. Nevertheless, several investigators have recently considered it desirable to re-examine the position of glutethimide in view of the findings associated with its para-amino derivative.

As mentioned previously glutethimide was included by Rallison et al. (1967) in their rat studies and was found not to interfere with thyroid metabolism.

The effects of glutethimide on steroidogenesis in the rat adrenal in vitro have been studied by Johnston, Krisle \& Troop (1968). Relatively high concentrations $(20-30 \mathrm{mg} / 100 \mathrm{~g})$ of the drug were shown to inhibit corticosterone synthesis, this effect being demonstrable regardless of whether the glutethimide was administered to the rat prior to adrenalectomy or directly into the incubation fluid. The conversion of pregnenolone and of deoxycorticosterone to corticosterone is inhibited, indicating a block of $11 \beta$-hydroxylation. Glutethimide was also found to suppress 21 -hydroxylation as evidenced by a reduced conversion of $11 \beta$-hydroxyprogesterone to corticosterone. Chronic treatment of the intact rat with glutethimide significantly lowered the plasma corticosterone concentration but did not affect adrenal weight or cholesterol concentration.

Gaunt et al. (1968) have shown that intravenous glutethimide has no effect on cortisol secretion in dogs except at high, near lethal, dosages (approximately $50 \mathrm{mg} / \mathrm{kg}$ ) whereas aminoglutethimide is active at $10 \mathrm{mg} / \mathrm{kg}$. These same workers have also drawn attention to the fact that high doses of glutethimide, unlike aminoglutethimide may act in vivo as do other central depressants by suppressing ACTH release. This has been inferred from the observations that in dogs with endogenous ACTH production blocked by dexamethasone, aminoglutethimide inhibits the steroidogenic response to an ACTH infusion whereas glutethimide at doses of $50 \mathrm{mg} / \mathrm{kg}$ does not.

Glutethimide was also included in the series of glutarimides examined in vitro by Kahnt \& Neher (1966), for effects on corticosteroid synthesis. This particular work showed that a hydrazide derivative, known as CIBA 17368-Ba, in a concentration of $6 \mu \mathrm{g} / \mathrm{ml}$ completely blocked corticosteroid synthesis by inhibition of 20-hydroxylation of cholesterol. Para-aminoglutethimide and ortho-aminoglutethimide produced similar inhibition at a concentration of $30 \mu \mathrm{g} / \mathrm{ml}$ but concentrations of $60 \mu \mathrm{g} / \mathrm{ml}$ of both glutethimide and phenglutethimide failed to have any effect. Phenytoin and the barbiturates were also included in this work and also failed to have any effect. Cohen (1968) has shown that glutethimide can be made to inhibit the desmolase enzyme complex but it was far less potent $(<1 \%)$ than aminoglutethimide in this respect.

These experimental findings are brought into clinical perspective by the work of McMahon \& Foley (1967) who have reported a double-blind comparison of glutethimide, quinalbarbitone and placebo. Each treatment was given for 7 days and the glutethimide was administered at the maximum recommended dose of $1 \mathrm{~g}$ daily. In this trial adrenal cortical response to ACTH remained normal and no differences appeared between the three treatment groups. That glutethimide was found not to interfere with adrenal cortical metabolism in normal clinical dosage was not surprising since the drug has been in widespread use as a hypnotic for 12 years and it seems unlikely that serious endocrinological sideeffects would have passed unnoticed during this time. Furthermore, the evidence available on the fate of orally administered glutethimide (Keberle, 1962) and aminoglutethimide (Douglas \& Nicholls, 1965), in man, suggests that the metabolism of these two drugs may differ significantly.

The clinical literature of phenglutarimide, a parasympatholytic substance in limited use for controlling disorders of extra-pyramidal origin affecting muscular tonus and motor function, contains no references to endocrinological side-effects.

\section{The future for aminoglutethimide}

The experimental studies previously cited indicate that the most important single action of aminoglutethimide is the inhibition of adrenal steroid biosynthesis immediately prior to the production of delta-5 pregnenolone. It would, therefore, seem reasonable to employ aminoglutethimide clinically in patients where it is desirable to block the production of the whole range of adrenal steroids. In practice, however, the main interest has so far been directed to clinical problems in patients with excessive cortisol and aldosterone production.

In most cases of Cushing's disease surgical treatment is satisfactory, but there is a small number where the operation is unsuccessful, only partially successful, or cannot be contemplated because of extensive neoplasia. In such cases treatment with drugs which will block adrenal metabolism is considered.

Hitherto adrenal blockers have comprised such drugs as metyrapone, which inhibits specific pathways of steroid synthesis (Gaunt, Chart \& Renzi, 1965), or toxic agents such as ortho-para-DDD which may produce profound constitutional disturbance (Weisenfeld \& Goldner, 1962). Aminoglutethimide in doses of up to $1000 \mathrm{mg}$ daily only 
rarely produces serious toxic effects, as has been described previously, and by its interference with both cortisol and aldosterone production can ameliorate the most severe symptoms of Cushing's syndrome, with or without the addition of substitution therapy.

In patients with Cushing's syndrome secondary to pituitary and hypothalamic disease, falls in cortisol production are largely compensated for by increased production of pituitary ACTH and so to some extent 'cortisol blocking' is self-defeating in that increased ACTH production may overcome the block. Not all cases, however, are pituitary-dependent and primary adrenal tumours would be expected to respond satisfactorily, as would cases where the production of ACTH was relatively fixed, such as with an ectopic ACTH-secreting tumour.

The first case of metastatic adrenal cancer treated with aminoglutethimide was reported by Schteingart, Cash \& Conn in 1966. This patient, with multiple metastases from adrenal carcinoma, was first treated with $o p^{\prime}$-DDD for 55 days and developed severe toxic effects including nausea, abdominal cramp, diarrhoea, weight loss, lethargy and ataxia. Subsequently aminoglutethimide in a dose of $250 \mathrm{mg}$ every $6 \mathrm{hr}$ was given and supplemented after 8 days with corticosteroids because of adrenal insufficiency. Thereafter a continuous remission of the Cushing's syndrome was maintained for 182 days without evidence of toxicity, and the tumour tissue apparently remained stationary. Also the aminoglutethimide, as well as exerting a prompt adrenal blocking effect, decreased the rate of cortisol turnover which was not observed with $o p^{\prime}$-DDD.

Similar therapeutic results have subsequently been described by Philbert et al. (1966); Smilo, Earll \& Forsham, (1967); Fishman et al. (1967); Horky et al. (1968) and Bochner et al. (1969). The latter authors have carefully compared the effects of aminoglutethimide and $o p^{\prime}$-DDD. The efficacy of the treatments were judged by measurement of a pulmonary metastasis and by urinary $170 \mathrm{HCS}$ excretion. $o p '$-DDD alone caused a gradual dimunition in size of the metastasis and some fall in 17OHCS excretion but no improvement in the hypercortisolism. The metastasis ceased to regress after withdrawal of the $o p^{\prime}$-DDD for a week. When aminoglutethimide was given alone there was an increase in size of the metastasis and evidence of adrenal insufficiency. $o p^{\prime}$-DDD was reintroduced resulting in a possible regression of the metastasis. The authors concluded that $o p^{\prime}$-DDD retards proliferation of adrenocortical carcinoma and aminoglutethimide reduces hormone secretion by the tissue. The effect of aminoglutethimide on proliferation may not be favourable and requires further study. Nevertheless, the combined use of these drugs offers a prospect of progress in the treatment of the disease.

In all cases of adrenal neoplasm the inhibition of cortisol and aldosterone production has been rapid, usually necessitating supplementary glucocorticoid therapy. Philbert et al. (1966) have suggested that the rapid fall in cortisol secretion is more important than the actual plasma level attained (cf. insulin hypoglycaemia) and Horký et al. (1968), who have reported on the use of aminoglutethimide in thirtysix patients, some treated for more than 1 year, consider that conservative use of the drug enhances the ultimate prognosis of surgical treatment by improving protein metabolism and electrolyte disturbances prior to surgery.

In contrast to the cases with adrenal neoplasm, those with bilateral adrenal hyperplasia have responded less well to aminoglutethimide, presumably as a result of compensatory increases in ACTH secretion (Smilo et al. 1967). Fishman et al. (1967), measuring plasma ACTH in normal subjects on aminoglutethimide found a consistent rise in plasma ACTH values. In patients with ectopic ACTH production, such as is occasionally seen with carcinoma of the bronchus, the compensatory increase in endogenous ACTH was not seen until cortisol secretion had fallen to very low levels. Such cases frequently showed relief of Cushingoid features, although there is no evidence of any effect on the tumour tissue. Such cases have been reported by Schteingart \& Conn (1967), Bower \& Harvey (1967), Gorden et al. 1968) and Horký et al. (1968).

One of the most consistent effects of aminoglutethimide has been the fall in aldosterone secretion which occurs irrespective of any increase in plasma renin activity. It is not surprising, therefore, that patients with primary and secondary aldosteronism have been treated with aminoglutethimide. Fishman et al. (1967) reported increases in serum plasma potassium, sodium diuresis and decrease in blood pressure in two out of three patients with primary aldosteronism. In a case of hyperaldosteronism secondary to hepatic cirrhosis there was an increase in urinary sodium and decrease in potassium, but little change in blood pressure, cortisol secretion rate, plasma $170 \mathrm{OCS}$ or urinary $17 \mathrm{KS}$. The results presented by Horký et al. (1968) in patients with hyperaldosteronism secondary to idiopathic oedema and ascitic cirrhosis of the liver were more favourable. These investigators also commented on the drug's marked diuretic effect and they found it extremely useful for lowering blood pressure in those patients with severe hypertension. Similarly Woods et al. (1969) have recently concluded that $20 \%$ of hypertensive patients have suppressed plasma renin activity and these patients differ from 
those with normal renin values in that they have significantly higher exchangeable sodium values and they also respond to aminoglutethimide with a significant decrease in blood pressure. These workers have suggested either that such patients have an unidentified mineralcorticoid present in excessive quantities or that normal levels of aldosterone play a supporting role in the hypertensive process.

The use of aminoglutethimide for the treatment of advanced metastatic carcinoma of the breast in nine patients in whom surgery was impossible has been reported by Hall et al. (1969). All patients also receive $0.75 \mathrm{mg}$ of dexamethasone daily and $0.4 \mathrm{mg}$ of fludrocortisone daily. Three patients had demonstrated objective regressions of tumour which persisted for up to 9 months. There was no uniform suppression of $17 \mathrm{OHCS}$ or $17 \mathrm{KS}$ or oestrogen production during aminoglutethimide therapy and the anti-tumour response was not related to the characteristic changes in the urinary steroid pattern. These authors, therefore, concluded that the occurrence of responses in patients with non-suppressed adrenals was due either to the suppression of an unknown steroid by aminoglutethimide or to a direct action of the drug itself on the tumours.

The results of clinical studies currently in progress in the United States and the United Kingdom in adrenal-endocrine disorders and hormone dependent' tumours are now being awaited with interest. It seems likely that these studies may establish new therapeutic uses for aminoglutethimide. However, until such time as results become available the original assessment by Philbert et al. (1966) still provides a very useful guide to the therapeutic use of aminoglutethimide. These investigators outline the major indications for aminoglutethimide as:-

Secreting tumours of the adrenal gland, metastatic or non-metastatic.

Non-adrenal neoplastic conditions associated with Cushingoid features.

Failure of bilateral adrenalectomy for the treatment of functional hypercorticism.

Of relative importance they place:-

Bilateral adrenal hyperplasia, including the preparation of patients for surgery.

Primary hyperaldosteronism.

Whatever the outcome of future inevstigations it now seems certain that aminoglutethimide will eventually be better known for its inhibition of adrenal metabolism than for its anticonvulsant activity.

Note: Aminoglutethimide is still under clinical trial in the United Kingdom and is not available commercially.

\section{References}

Aguilar, J.A., Martin, H.L. \& McNaughton, F.L. (1961) Aminoglutethimide in the treatment of epilepsy. Canadian Medical Association Journal, 84, 374.
Bochner, F., Lloyd, H.M., Roeser, H.P. \& Thomas, M.J. (1969) Effects of $c p^{\prime}$-DDD and aminoglutethimide on metastatic adrenocortical carcinoma. Medical Journal of Australia, 1, 809.

Bower, B. \& Harvey, W. (1968) Aminoglutethimide (Elipten) in the therapy of Cushing's syndrome secondary to ACTH-producing nonendocrine carcinoma. Hartford Hospital Bulletin, 23, 132.

BraY, P.F. (1959) Diphenylhydantoin (dilantin) after 20 years; a review with re-emphasis treatment of 84 patients. Paediatrics, 23, 151.

Camacho, A.M., Brough, A.J., Cash, R. \& Wilroy, R.S. (1966) Adrenal toxicity associated with the administration of an anticonvulsant drug. Journal of Paediatrics, 68, 852.

Camacho, A.M., CaSh, R., Brough, A.J. \& Wilroy, R.S. (1967) Inhibition of adrenal steroidogenesis by aminoglutethimide and the mechanism of action. Journal of the American Medical Association, 202, 20.

Cash, R., Brough, A.J., Cohen, M.N.P. \& Satoh, P.S. (1967) Aminoglutethimide (Elipten-Ciba) as an inhibitor of adrenal steroidogenesis: mechanism of action and therapeutic trial. Journal of Clinical Endocrinology and Metabolism, 27, 1239.

Cash, R., Petrini, M.A. \& Brough, A.J. (1969) Ovarian dysfunction associated with an anticonvulsant drug. Journal of the American Medical Association, 208, 1149.

COHEN, M.P. (1968) Aminoglutethimide inhibition of adrenal desmolase activity. Proceedings of the Society for Experimental Biology and Medicine, 1086.

Defer, B. (1960) Essais cliniques d'un nouvel anti-comitial, le C.16.038. Maroc Médicale, 39, 823.

Dexter, R.N., Fishman, L.M., Black, A.C. \& Ney, R.L. (1966) Inhibition of adrenal corticosteroid synthesis by amino-glutethimide. Clinical Research. 14, 61.

Dexter, R.N.. Fishman, L.M., Ney, R.L., Liddle, G.W. (1967) Inhibition of adrenal corticosteroid synthesis by aminoglutethimide: studies of the mechanism of action. Journal of Clinical Endocrinology and Metabolism, 27, 473.

Douglas, J.S. \& Nicholls, P.J. (1965) The urinary excretion of aminoglutethimide in man. Journal of Pharmacy and Pharmacology, 17, 115S.

Eversole, W.J. \& ThOMPSON, D.J. (1967) Effects of aminoglutethimide on ovarian structure and function. Federation Proceedings, 26, 535.

FABISCH, W. (1959) A clinical trial with a new anticonvulsant drug $\alpha$-(P-aminophenyl)- $\alpha$-ethyl glutarimide preparation 16038 (CIBA). Journal of Mental Science, 105, 448.

Fishman, L.M., Liddle, G.W., Island, D.P., Fleischer, N \& KUCHEL, O. (1967) Effects of amino-glutethimide on adrenal function in man. Journal of Clinical Endocrinology' and Metabolism, 27, 481 .

Gaunt, R., Chart, J.J. \& Renzi, A.A. (1965) Inhibitors of adrenal corticol function. Ergebnisse der Physiologie, biologischen Chemie und experimentellen Pharmakologie, 56, 114.

Gaunt, R. Steinetz, B.G. \& Chart, J.J. (1968) Pharmacologic alteration of steroid hormone functions. Clinical Pharmacology and Therapeutics, 9, 657.

Givens, J.R., Coleman, S. \& Britt, L. (1968) Anatomical changes producted in the human adrenal cortex by aminoglutethimide. Clinical Research, 16, 441.

Gorden, P., Becker, C.E., Levey, G.S. \& Roth, J. (1968) Efficacy of amino-glutethimide in the ectopic ACTH syndrome. Journal of Clinical Endocrinology and Metabolism, 28, 921 .

Gross, F., Hoffman, K., Kebrle, J. \& Tripod, J. (1956) Constitution, action and biological degradation of glutarimides. Verhandlungen der Naturforschenden Gesellschaft in Basel, 67, 479. 
Guareschi, A., Giannelli, A. \& Marinato, G. (1956) L'azione di un nuovo derivato dell'imide glutarica (16038) sulla epilessia stricnica corticale. Rivista di Neurologica, 26, 342.

Hagen, A.A., Butler, F.M. (1969) The influence of aminoglutethimide on the catabolism of cortisol-4- $\mathrm{C}^{14}$ in the human. Federation Proceedings, 28, 579.

Hall, T., Barlow, J., Griffiths, C. \& Saba, Z. (1969) Treatment of metastatic breast cancer with aminoglutethimide. Clinical Research, 17, 402.

HORKÝ, K. \& KüCHEL, O. (1969). Aminoglutethimide (elipten-Ciba)-a new inhibitor of steroid biosynthesis. Annals of Iniernal Medicine, 70, 866.

Horký, K., Küchel, O., Gregorova, I., Jirankova, J. \& MATYS, Z. (1968) Klinische erfahrungen mit aminoglutathimid (Elipten), einem neuen inhibitor der steriodbiosynthese in der nebenniere. Schweizersche medizinische Wochenschrift, 98, 1843.

Iffy, L., Ansell, J.S., Bryant, J.S. \& Herrmann, W.L. (1965) Nonadrenal female pseudohermaphroditism: an unusual case of fetal masculinization. Obstetrics and Gynecology, 26, 59.

Johnston, G.G., Krisle, J.R. \& Troop, R.C. (1968) Inhibition of adrenal steroidogenesis by glutethimide. Proceedings of the Society for Experimental Biology and Medicine, 129, 20.

Journal of the American Medical Association (1962), 179, 798.

KahNT, F.W. \& Neher, R. (1966) On the adrenal biosynthesis of steroids in vitro. Part III. Selective inhibition of adrenocortical function. Helvetica Chimica Acta, 49, 725.

Keberle, H. (1962) The Metabolism of glutethimide (Doriden $\mathbf{R})$. Experientia, 18, 105.

Kowal, J. (1967) A possible system for studying ACTH action during complete steroidogenic blockade. Clinical Research, 15, 455.

LAMBRos, V.S. (1958) A new anticonvulsant, Elipten TM. Diseases of the Nervous System, 19, 349.

LAVECK, G.D. (1960) Elipten in the Treatment of Organic Epilepsy. Diseases of the Nervous System, 21, 230.

Livingstone, S., Petersen, D. \& Boks, L.L. (1955) Hypertrichosis occurring in association with dilantin therapy. Journal of Paediatrics, 47, 351.

Livingstone, S. (1956) Treatment of epilepsy with diphenylhydantoin sodium (dilantin sodium). Postgraduate Medicine, 20, 584.

McMahon, F.G. \& Foley, J. (1967) Lack of glutethimide effect on adrenal. Journal of Clinical Endocrinology and Metabolism, 27, 1495.

Pearce, K.I. (1960) Elipten: A clinical evaluation of a new anticonvulsant. Canadian Medical Association Journal, 82 953.
Philbert, M., Laudat, M.H., Laudat, Ph. \& Bricaire, A. (1966) Etude clinique et biologique d'un inhibiteur de l'hormonosynthèse corticosurrenale: l'aminoglutethimide. Annales d'endocrinologie, 29(2), 189.

Pittman, J.A. \& Brown, R.W. (1966) Antithyroid and antiadrenocortical activity of aminoglutethimide. Journal of Clinical Endocrinology and Metabolism, 26, 1014.

Rallison, M.L., TyleR, F.H. \& KUMAGI, L.F. (1964) Goitrous hypothyroidism induced by an anticonvulsant drug. Journal of Paediatrics, 65, 1085.

Rallison, M.L., Kumagi, L.F. \& Tyler, F.H. (1967) Goitrous hypothyroidism induced by amino-glutethimide, anticonvulsant drug. Journal of Clinical Endocrinology and Metabolism, 27, 265.

SchteingarT, D.E., Cash, R. \& Conn, J.W. (1966) Aminoglutethimide and metastatic adrenal cancer. Journal of the American Medical Association, 198, 1007.

SChTEINGART, D.E. \& ConN, J.W. (1967) Effects of aminoglutethimide upon adrenal function and cortisol metabolism in Cushing's syndrome. Journal of Clinical Endocrinology and Metabolism, 27, 1657.

SHEEHAN, S. (1958) One thousand cases of late onset epilepsy. Irish Journal of Medical Science, 6, 261.

Sheppard, H., Beasley, J.H. \& Wacker, J.L. (1966) The influence of NADPH or its generating system on corticosteroid biosynthesis by rat adrenal homogenates. Federation Proceedings, 25, 551 .

Smilo, R.P., EARll, J.M. \& Forsham, P.H. (1967) Suppression of tumerous adrenal hyperfunction by aminoglutethimide. Metabolism, 16, 374.

SPARBERG, M. (1963) Diagnostically confusing complications of diphenylhydantoin therapy: A review. Annals of Internal Medicine, 59/6, 914.

VeRDEAU-PAILles, J. (1961) Un nouvel anticonvulsant: La preparation CIBA 16-0-38 ou eliptene. Annales medicopsychologiques, 119, 501 .

Weisenfeld, S. \& Goldner, M.G. (1962) Treatment of advanced malignancy and Cushing's syndrome with DDD. Cancer Chemotherapy Abstracts, 16, 335.

Werk, E.E., MacGee, J. \& Sholiton, L.J. (1964) Effect of diphenylhydantoin on corticol metabolism in man. Journal of Clinical Investigation, 43, 1824.

Wilroy, R.S., Camacho, A.M., Trouy, R.L. (1966) Inhibition of adrenal steroidogenesis by aminoglutethimide. Southern Medical Journal, 59, 1477.

Woods, J.W., Hill, C., Liddle, G.W., Stant, E.G., MichelaKis, A.M. \& Brill, A.B. (1969) Effect of an adrenal inhibitor in hypertensive patients with suppressed renin. Archives of Internal Medicine, 123, 366.

Zavadil, M., Schreiber, V., Kmentova-Zbuzkova, V. (1968) Die veranderungen am ovarium von ratten nach applikation von aminoglutethimid (elipten-Ciba). Endocrinologicie, 53, 405. 